\title{
In Vitro Antimicrobial Susceptibility of Corynebacterium pseudotuberculosis Isolated from Sheep with Caseous Lymphadenitis
}

\author{
Ziya İLHAN* \\ Balkesir University, Faculty of Veterinary Medicine, Department of Microbiology, Ballkesir, Turkey
}

\begin{abstract}
Caseous lymphadenitis (CLA), caused by Corynebacterium pseudotuberculosis, is a highly prevalent disease of sheep and goats resulting in significant economic losses in the world. In this study, it was aimed to determine the in vitro antimicrobial susceptibility of $C$. pseudotuberculosis strains isolated from sheep with CLA to various antibiotics. A total of 16 C. pseudotuberculosis strains isolated from lung samples of 67 sheep with CLA lesions were tested. Tetracycline, oxytetracycline, streptomycin, enrofloxacin, cloxacillin, ampicillin/sulbactam, amoxicillin/clavulanic acid, penicillin/novobiocin, trimethoprim/sulfamethoxazole and neomycin/bacitracin/tetracycline discs were tested by disc diffusion method. A total of $14(87.5 \%)$ C. psendotuberculosis strains were susceptible to enrofloxacin, $13(81.2 \%)$ strains to neomycin/bacitracin/tetracycline, $12(75.0 \%)$ strains to penicillin/novobiocin, $11(68.7 \%)$ strains to oxytetracycline, $11(68.7 \%)$ strains to amoxicillin/clavulanic acid, $10(62.5 \%)$ strains to cloxacillin, 9 $(56.2 \%)$ strains to tetracycline, $5(31.2 \%)$ strains to ampicillin/sulbactam and $3(18.7 \%)$ strains to trimethoprim/sulfamethoxazole. None of the isolates were susceptible to streptomycin.
\end{abstract}

Keywords: Antimicrobial susceptibility testing, Caseous lymphadenitis, Corynebacterium psendotuberculosis

\author{
$* * *$ \\ Kazeöz Lenfadenitisli Koyunlardan İzole Edilen \\ Corynebacterium pseudotuberculosis Suşlarının in-Vitro Antibiyotik Duyarlılıkları
}

ÖZ

Koyun ve keçilerde Corynebacterium pseudotuberculosis tarafindan oluşturulan kazeöz lenfadenitis (KLA), tüm dünyada yaygın olarak görülmekte ve önemli ekonomik kayıplara neden olmaktadır. Bu çalışmada, KLA'li koyunlardan izole edilen C. pseudotuberculosis suşlarının çeşitli antibiyotiklere in vitro duyarllıklarının belirlenmesi amaçlandı. Çalışmada KLA lezyonları gösteren toplam 67 adet koyunun akciğerlerinden izole edilen 16 adet $C$. pseudotuberculosis suşu test edildi. Disk difüzyon yöntemiyle yapılan değerlendirmede; tetrasiklin, oksitetrasiklin, streptomisin, enrofloksasin, kloksasilin, ampisilin/sulbaktam, amoksisilin/klavulanik asit, penisilin/novobiosin, trimetoprim/sulfametaksazol ve neomisin/basitrasin/tetrasiklin diskleri kullanıldı. Suşların 14 (\%87.5) adeti enrofloksasine, $13(\% 81.2)$ adeti neomisin/basitrasin/tetrasikline, $12(\% 75.0)$ adeti penisilin/novobiosine, 11 (\%68.7) adeti oksitetrasikline, 11 (\%68.7) adeti amoksisilin/klavulanik asite, 10 (\%62.5) adeti kloksasiline, 9 $(\% 56.2)$ adeti tetrasikline, 5 (\%31.2) adeti ampisilin/sulbaktama ve $3(\% 18.7)$ adeti ise trimetoprim/sulfametaksazole duyarlı bulundu. İzolatlardan hiçbiri streptomisine duyarlı bulunmadı.

Anahtar Kelimeler: Antibiyotik duyarll11k testi, Corynebacterium pseudotuberculosis, Kazeöz lenfadenitis

To cite this article: Ilhan Z. In Vitro Antimicrobial Susceptibility of Corynebacterium pseudotuberculosis Isolated from Sheep with Caseous Lymphadenitis. Kocatepe Vet J. (2020) 13(3):267-271

Submission: 17.05.2020 Accepted: 13.07.2020

Published Online: 28.08 .2020

ORCID ID; Zİ: 0000-0003-3638-9196

*Corresponding author e-mail: zilhan@balikesir.edu.tr 


\section{GİRİŞ}

Corynebacterium pseudotuberculosis Gram pozitif, hareketsiz, sporsuz, kapsülsüz, kokoid veya çomak morfolojisinde, fakültatif intraselüler bir bakteridir. Bakteri $37^{\circ} \mathrm{C}$ 'de, aerobik veya fakültatif anaerobik ortamlarda, 2-4 günde küçük, yuvarlak, sarımsı veya gri-beyaz renkte, agar yüzeyinde kayan koloniler oluşturmaktadır. Proteolitik etkisi olmayan etkenin, biyokimyasal aktivitesi zayıf ve değişkendir. $C$. pseudotuberculosis'in nitrata olan etkisi bakimindan, nitrat negatif ve pozitif olmak üzere farklı suşları bulunmaktadır. Genel olarak koyun ve keçi orijinli suşlar nitrat negatif, at ve sığır orijinliler ise nitrat pozitiftir (Dorella ve ark. 2006, Quinn ve ark. 2011).

C. pseudotuberculosis insan dahil çeşitli canlı türlerinde değişik enfeksiyonlara neden olmaktadır (Kuria ve Holstad 1989, Dorella ve ark. 2006, Bastos ve ark. 2012). Bakteri daha çok koyun ve keçilerde kazeöz lenfadenitis (KLA)'in spesifik etkeni olarak bilinmektedir. KLA, özellikle eksternal lenf yumruları (eksternal form) ve akciğerler başta olmak üzere çeşitli iç organlarda kapsüllü apselerin oluşumuyla karakterize (internal form), kronik bir enfeksiyondur. Dünyanın birçok bölgesinde yaygın olarak görülen enfeksiyonda apseleşmeyle birlikte erken doğum, yavru atma, deri ve yapağı kalitesinde bozulma, ileri derecede zayıflamaya bağlı olarak et verimi ve kalitesinde düşme, genç hayvanlarda daha fazla olmak üzere nadiren de olsa ölümler görülebilmektedir (Middleton ve ark. 1991, İlhan 2001, Dorella ve ark. 2006, Parin ve ark. 2018).

KLA'in tedavisinde çeşitli antimikrobiyal maddeler kullanılmaktadır. Etkenin çeşitli antibiyotiklere in vitro duyarlılığına yönelik bazı çalışmalar yapılmıştır. Kanada'da yapılan bir çalışmada, KLA'li keçilerden izole edilen toplam 26 adet $C$. pseudotuberculosis suşu test edilmiş ve izolatlardan 3'ünün neomisine, tamaminin ise ampisilin, kloramfenikol, linkomisin, gentamisin, tetrasiklin, penisilin $G$ ve trimetoprim/sulfametaksazole duyarlı olduğu rapor edilmiştir. Aynı çalışmada tüm izolatların streptomisine ise dirençli olduğu bildirilmiştir (Muckle ve Gyles 1982). Fransa'da 6 farklı coğrafi bölgede yetiştirilen KLA'li koyun ve keçilerden elde edilen 22 adet C. pseudotuberculosis suşuyla yapılan çalışmada, izolatlardan birinin yüksek düzeyde streptomisine dirençli olduğu ifade edilmiştir (Pepin ve ark. 1989). İspanya'da subklinik mastitisli koyun orijinli 10 adet C. pseudotuberculosis suşunun incelendiği araştırmada; amoksisilin, penisilin, tetrasiklin, kanamisin, gentamisin, eritromisin, rifampisin, linkomisin, siprofloksasin, doksisilin ve kloramfenikol test edilmiştir. Araştırmada sonuç olarak, izolatların tamamının MİK değerlerinin oldukça yüksek olduğu rapor edilmiştir (Fernández ve ark. 2001). Sa ve ark. (2013), Brezilya'da KLA'li koyun ve keçilerden izole ettikleri toplam 398 adet C. pesudotuberculosis suşuyla yaptiklar1 antibiyogram testinde; izolatlarin \%100'ünün florfenikol ve tetrasikline, \%99.2'sinin linkomisin, enrofloksasin ve siprofloksasine, $\% 98.9$ 'unun sefalotine, \%98.7'sinin norfloksasine, $\% 97.7$ 'sinin gentamisine, \%94.2'sinin ampisiline, \%91.2'sinin penisilin G'ye ve \%89.2'sinin neomisine duyarli; \%100'ünün ise novobiyosine dirençli olduğunu bildirmişlerdir.

Yapılan çalışmalar dikkate alındığında, KLA'li hayvanlardan izole edilen $C$. pseudotuberculosis suşlarının in vitro antibiyotik duyarlilıklarının belirlenmesinde, çeşitli antimikrobiyal maddelerin kullanıldı̆̆ı ve bu çalışmalardan oldukça farklı sonuçların alındığı görülmektedir. Bu çalışmada, Balıkesir ilinde KLA'li koyunlardan izole edilen $C$. pseudotuberculosis suşlarının çeşitli antimikrobiyal maddelere in vitro duyarlılıklarının belirlenmesi amaçlandı.

\section{MATERYAL ve METOT}

\section{Materyal}

Çalışma kapsamında toplam 67 adet koyun akciğer örneği materyal olarak kullanıldı. Materyaller, Bigadiç Belediye Mezbahasinda Eylül 2018-Nisan 2019 tarihleri arasinda kesimi yapilan koyunlardan topland. Kesimi yapılan hayvanların akciğerleri, veteriner hekimler tarafindan kontrol edildi. Örnekler, makroskopik olarak pnöymoni belirtileri gözlenen ve apseleşmiş lenf yumruları (bronşiyal ve mediastinal) saptanan hayvanlardan alındi. Kesim sonrasinda yaklaşık 10-15 gr. ağırlığında temiz plastik kaplara konulan örnekler, soğuk zincirde ve kisa sürede Balıkesir Üniversitesi Veteriner Fakültesi Mikrobiyoloji Anabilim Dalı Laboratuvarına ulaştırıld1.

\section{İzolasyon}

Akciğer örneklerinden steril svaplarla \%5-7 defibrine koyun kanlı agara (1.10886, Merck, Darmstadt, Germany) ekimler yapıldı. Petri kutuları $37^{\circ} \mathrm{C}$ 'de ve aerobik ortamda 1-3 gün inkube edildi. Besiyerinde şekillenen koloniler makroskopik ve mikroskopik morfolojileriyle birlikte, çeşitli biyokimyasal özelliklerine göre C. pseudotuberculosis olarak identifiye edildi (Dorella ve ark. 2006, Quinn ve ark. 2011).

\section{Antibiyotik duyarlılık testi}

$\mathrm{Bu}$ amaçla, akciğer örneklerinden identifiye edilen $C$. pseudotuberculosis suşları brain heart infusion brotta (CM1135, Oxoid, Basingstoke, England) aerobik atmosferde, $37^{\circ} \mathrm{C}$ 'de üretildi (McFarland Standart Tüp No: 0.5). Test, plate count agarda (105463, Merck), Kirby-Bauer Disk Difüzyon Yöntemime göre yap1ld1 (Bauer ve ark. 1966). Teste; tetrasiklin (30 $\mu \mathrm{g}$, Oxoid), oksitetrasiklin (30 $\mu \mathrm{g}, \quad$ Bioanalyse), streptomisin (10 $\mathrm{g}$, Bioanalyse), enrofloksasin (5 $\mu \mathrm{g}$, Bioanalyse), kloksasilin (5 $\mu \mathrm{g}, \quad$ Oxoid), ampisilin/sulbaktam (10/10 $\mu \mathrm{g}) \quad$ (Bioanalyse), amoksisilin/klavulanik asit (2/1) (30 $\mu$ g, Oxoid), penisilin/novobiosin (40 $\mu \mathrm{g}, \quad$ Oxoid), trimetoprim/sulfametaksazol $(1.25 \mu \mathrm{g} / 23.75 \mu \mathrm{g}$, 
$\mathrm{BBC}$ ) ve neomisin/basitrasin/tetrasiklin (30 $\mu \mathrm{g} / 10$ $\mathrm{IU} / 30 \mu \mathrm{g}$, Mast Diagnostic) diskleri kullanıldi. Sonuçlar, besiyerleri $37^{\circ} \mathrm{C}$ 'de 24 saat inkübe edildikten sonra değerlendirildi (CLSI 2013).

\section{BULGULAR}

\section{İzolasyon}

Incelen 67 adet akciğer örneğinin 16 (\%23.8)'sından C. psendotuberculosis izole edildi. Etken 9 (\%56.2) örnekte saf kültür olarak, 7 (\%43.8) örnekte ise çeşitli
Gram pozitif ve negatif bakteriyel etkenlerle birlikte üredi.

\section{Antibiyotik duyarlilık testi}

Toplam 16 adet C. pseudotuberculosis suşunun kullanıldı̆̆ı bu çalışmada, test edilen antimikrobiyal maddeler arasinda en yüksek duyarlilık (\%87.5) enrofloksasine karşı saptanırken, izolatların tamamının streptomisine dirençli olduğu görüldü (Tablo 1).

Tablo 1: C. pseudotuberculosis suşlarının in vitro antimikrobiyal duyarlılı̆̆1.

Table 1. In vitro antimicrobial susceptibility of C. pseudotuberculosis strains.

\begin{tabular}{cccc}
\hline Antimikrobiyal Madde & \multicolumn{3}{c}{ İzolat Sayisi (\%) } \\
\cline { 2 - 4 } & Duyarlı & Duyarlı & Dirençli \\
\cline { 2 - 4 } & & & \\
Enrofloksasin & $14(87.5)$ & $1(6.2)$ & $1(6.2)$ \\
Neomisin/basitrasin/tetrasiklin & $13(81.2)$ & $2(12.5)$ & $1(6.2)$ \\
Penisilin/novobiosin & $12(75.0)$ & $0(0.0)$ & $4(25.0)$ \\
Oksitetrasiklin & $11(68.7)$ & $1(6.2)$ & $4(25.0)$ \\
Amoksisilin/klavulanik asit & $11(68.7)$ & $2(12.5)$ & $3(18.7)$ \\
Kloksasilin & $10(62.5)$ & $3(18.7)$ & $3(18.7)$ \\
Tetrasiklin & $9(56.2)$ & $4(25.0)$ & $3(18.7)$ \\
Ampisilin/sulbaktam & $5(31.2)$ & $0(0.0)$ & $11(68.7)$ \\
Trimetoprim/sulfametaksazol & $3(18.7)$ & $1(6.2)$ & $12(75.0)$ \\
Streptomisin & $0(0.0)$ & $1(6.2)$ & $15(93.7)$ \\
\hline
\end{tabular}

\section{TARTIŞMA}

KLA tüm dünyada yayg1n olarak görülen ve küçük ruminant endüstrisinde önemli ekonomik kayılara neden olan bir enfeksiyondur. OIE'nın raporuna göre 1996-2004 yılları arasinda 201 farklı ülkeden alınan veriler değerlendirilmiş ve 64 ülkede enfeksiyonun varlığ1 bildirilmiștir. Bu ülkelerin 19'u Amerika Kitasinda, 18'i Afrika Kitasinda, 14'ü Avrupa Kitasinda, 11 Asya Kitasinda ve 2'si de Okyanusya'da bulunmaktadır (OIE 2009). Ülkelere göre enfeksiyonun prevalansıyla ilgili oldukça farklı değerler bulunmaktadır. Bu değerler yaklaşık \%8-90 arasında değişmektedir (Kuria ve Holstad 1989, Middleton ve ark. 1991, Stanford ve ark. 1998, Ali ve ark 2016). KLA'in prevalansiyle ilgili değerlendirmeler, genellikle enfeksiyonun eksternal formunda görülen lezyonlara göre yapilmaktadır. Ancak hastalığın gerçek prevalansının saptanmasında internal forma ait lezyonların da mutlaka dikkate alınması gerektiği bildirilmektedir (Abebe ve Tessema 2015). Gerçekleştirilen bu çalışmada, Balıkesir İlindeki koyunlarda KLA'in prevalans1 \%23.8 olarak saptanmıştır. Bu bulgu; incelenen hayvan sayısının az olması, istatistiksel bir örnekleme yönteminin/lerin uygulanmamas1 ve bazı nedenlerden dolay1 enfeksiyonun eksternal formuna ait semptom ve lezyonların yeteri düzeyde incelenememesi nedenleriyle, gerçek prevalans değeri olarak görülmeyebilir. Yine de bulgunun, konuyla ilgili bir ön çalışma olarak değerlendirilmesi olasıdır.

KLA'li koyun ve keçilerden izole edilen $C$. pseudotuberculosis suşlarının in vitro antimikrobiyal maddelere duyarlılıklarının belirlenmesinde, Türkiye'de daha az olmak üzere, bazı ülkelerde değişik çalışmalar yapılmıştır. Konya'da KLA'li koyunlardan izole edilen C. pseudotuberculosis suşlarının in vitro antimikrobiyal duyarlılı̆̆ının araştırıldığı bir çalışmada; izolatların florfenikol (\%98.6), telitromisin (\%91.6), enrofloksasin (\%83.3), penisilin G (\%83.3), oksitetrasiklin (\%81.9), rifampisin (\%81.9), gentamisin (\%81.9), amoksisilin (\%77.7), ampisilin/sulbaktam (\%76.3), eritromisin (\%69.4), spiramisin (\%58.3), kloksasilin (\%55.5) ve ampisiline (\%37.5) duyarlı olduğu ifade edilmiştir (Sakmanoğlu ve ark. 2015). Mısır'da yapılan bir çalışmada, klinik olarak KLA semptomları gösteren 80 adet koyun ve 46 adet keçinin ekstermal lenf yumrularından alınan örneklerin analizinden elde edilen 52 adet $C$. psendotucerculosis suşu test edilmiştir. En yüksek duyarlılığın siprofloksasin (\%96.2), amikasin (\%90.4), neomisin (\%88.5) ve streptomisine (\%80.8) karş1 olduğu çalışmada; penisilin $(\% 96.2)$ ve eritromisine (\%92.3) karş1 ise en yüksek dirençliliğin saptandığ1 rapor edilmiştir (Algammal 2016). Etiyopya'da 82 adet koyun ve keçiden alınan örneklerin bakteriyolojik 
analizinde, 59 (\%71.9) hayvandan C. pseudotuberculosis izole edilmiştir. Yapılan antibiyogram testinde izolatların 46's1 (\%77.9) norfloksasine, 43'ü (\%72.8) doksisilin ve tetrasikline, 41'i (\%69.4) kanamisin ve vankomisine, 35'i (\%59.3) ise ampisilin ve klindamisine duyarlı bulunmuştur (Abebe ve Tessema 2015). Sudan'da koyun ve keçilerden izole edilen toplam 66 adet C. pseudotuberculosis suşunun disk difüzyon yöntemiyle yapılan değerlendirilmesinde; $\% 86.7$ 'sinin nitrofurantaine, \% 78.8'inin kloramfenikol ve rifampisine, \%72.1'inin eritromisine, \%66.2'sinin ampisiline, \%65.2'sinin gentamisine, \% 59.1'inin ise tetrasikline duyarlı olduğu bildirilirken; izolatların \%100'ünün nalidiksik asit ve kolistine, \%87.9'unun penisiline ve \%72.7'sinin ise streptomisine dirençli olduğu ifade edilmiştir (Abdel Wahab ve Shigidi 2013). Robaj ve ark. (2017), Kosova'da 284 adet hayvandan oluşan bir koyun sürüsünde klinik olarak KLA semptomları gösteren 38 hayvandan aldıkları örnekleri kültüre ederek, 32 (\%84.2) hayvandan $C$. psendotuberculosis izole ettiklerini bildirmişlerdir. Araştırıcılar yaptıkları antibiyogram testinde; izolatlarin amoksisilin/klavulanik asit ve oksitetrasikline \%100, kloksasiline \%95.8, gentamisine $\% 91.7$, trimetoprim/sulfametaksazole $\% 83.3$ ve streptomisine \%16.7 oranında duyarlı olduğunu rapor etmişlerdir. Gerçekleştirilen bu çalışmada, izolatların $\% 87.5$ 'i enrofloksasine, $\% 81.2$ 'si neomisin/basitrasin/tetrasikline, $\quad \% 75.0^{\prime} \mathrm{i}$ penisilin/novobiosine, \%68.7'si oksitetrasiklin ile amoksisilin/klavulanik asite, \%62.5'i kloksasine, \%56.2'si tetrasikline, \%31.2'si ampisilin/sulbaktama ve $\% 18.7$ 'si ise trimetoprim/sulfametaksazole duyarlı bulunurken; tamamının ise streptomisine dirençli oldukları saptanmıştır. Konuyla ilgili çalışmalar birlikte değerlendirildiğinde, C. pesudotuberculosis suşlarının çeşitli antibiyotiklere olan duyarlık/dirençliliğinin oldukça farklılıklar gösterdiği görülmektedir. Bu durum, çalışmanın yapıldığı ülke ve bölgelerin farklı olmasıyla açıklanabileceği gibi izolasyon yapilan hayvanlara yönelik antibiyotik uygulamaları ve çalışmalarda uygulanan yöntemlerin farklılığıyla da (değişik besiyerlerinin kullanılması gibi) ilgili olabilir.

Diğer bakteriyel enfeksiyonlarda olduğu gibi KLA'in tedavisinde de en önemli rolü antibiyotikler üstlenmektedir. İlk antibiyotik olan penisilinin keşfinden itibaren hem beşeri hem de veteriner hekimlikte enfeksiyöz hastalıklarla mücadelede antibiyotiklerle önemli başarılar elde edilmiştir. Ancak ilk antibiyotiğin kullanımıla birlikte, muhtemelen ilk antimikrobiyal direnç de görülmeye başlamıştır. Günümüzde Dünya Sağlık Örgütü (WHO) başta olmak üzere, konuyla ilgili birçok kuruluş ve bilim insanı tarafindan gelişen antibiyotik dirençliliğine dikkat çekilerek, gelecekte yeni antibakteriyellerin bulunmaması halinde, bazı bakteriyel enfeksiyonların tedavisinde çok önemli sorunların yaşanabileceği bildirilmektedir (Lee ve ark. 2012, WHO 2020). Bakterilerin antibiyotiklere karşı direnç geliştirmesinde çeşitli faktörler rol oynamaktadır. Bunlardan belki de en önemlisi bilinçsizce ve rastgele antibiyotik kullanımıdır. Gerçekleştirilen bu çalışmada, KLA'in internal formundan izole edilen C. pseudotuberculosis suşlarının oldukça yüksek oranlarda streptomisin (\%93.7), trimetoprim/sulfametaksazol (\%75.0) ve ampisilin/sulbaktama (\%68.7) dirençli bulunmas1, bölgede koyunlara test yap1lmadan antibiyotik uygulanmasıyla ilgili olabilir. Diğer yandan bu durum, koyun orijinli C. pseudotuberculosis suşlarında söz konusu antibiyotiklere karşı çoğul direnç gelişimiyle de açılklanabilir.

Streptomisin 1943 y1linda Streptomyces griseus'tan elde edilen bir antibiyotik olup, daha çok Brucella spp. ve Mycobacterium spp. gibi fakültatif intraselüler bakteri enfeksiyonlarının tedavisinde kullanılmaktadır (Quinn ve ark. 2001; Alavi ve Alavi 2013). Bu çalışmada, fakültatif intraselüler bir bakteri olan $C$. pesudotuberculosis'in streptomisine yüksek oranda (\%93.7) dirençli olması, dikkat çekici bulunmuştur. Benzer durum, Kanada'da keçi orijinli (Muckle ve Gyles 1982), Fransa'da ise koyun ve keçi orijinli (Pepin ve ark. 1989) C. pesudotuberculosis suşlarıyla yapılan çalışmalarda da görülmektedir. Muckle ve Gyles (1982) ile Pepin ve ark. (1989) tarafindan yapılan çalışmaların yapıldıkları dönemler dikkate alındığında, antibiyotiklere ulaşım ve kullanım oranlarının günümüz ve yakın geçmişe göre oldukça düşük düzeyde olduğu düşünülebilir. Bu hipotezden hareketle, koyun ve keçi orijinli C. pesudotuberculosis suşlarının streptomisine yüksek düzeyde dirençli olmas1, söz konusu bakterinin streptomisine doğal dirençli olabileceği şeklinde değerlendirilebilir.

C. psendotuberculosis bir hayvan sürüsüne bulaştığında, enfeksiyonun kontrol altına alınmasında çeşitli sorunlar yaşanmaktadır. Bunlar arasında, hastalığın bazı vakalarda sub-klinik formda seyretmesi nedeniyle fazla sayıda hayvanın kisa sürede enfekte olması ve bakterinin hücre duvarındaki kalın lipit tabakası nedeniyle bazı antibiyotiklere dirençli olması sayılabilir (Abebe ve Tessema 2015). Bu durum dikkate alındığında, koyunlardaki KLA'in tedavisinde mutlaka antibiyotik duyarlılık test sonuçlarına göre tedavi stratejilerinin belirlemesi gerekmektedir. Sonuç olarak, rastgele ve uygunsuz antibiyotik kullanımı dirençli suşların yayılmasına neden olabildiği gibi tedavi giderlerinin de artmasına yol açmaktadır.

Çı1kar Çatışması: Yazarlar, çıkar çatışması olmadığını beyan eder

\section{KAYNAKLAR}

Abdel Wahab MB, Shigidi MTA. In vitro sensitivity of Corynebacterium pseudotuberculosis to 16 antimicrobial agents. Sudan J Vet Res. 2013; 28: 23-25.

Abebe D, Tessema TS. Determination of Corynebacterium pseudotuberculosis prevalence and antimicrobial susceptibility pattern of isolates from lymph nodes of 
sheep and goats at an organic export abattoir, Modjo, Ethiopia. Lett Appl Microbiol. 2015; 61: 469-476.

Alavi SM, Alavi L. Treatment of brucellosis: a systematic review of studies in recent twenty years. Caspian J Intern Med. 2013; 4(2): 636-641.

Algammal AM. Molecular characterization and antibiotic susceptibility of Corynebacterium pseudotuberculosis isolated from sheep and goats suffering from caseous lymphadenitis. Zagazig Vet J. 2016; 44 (1): 1-8.

Ali AD, Mahmoud AA, Khadr AM, Elshemey TM, Abdelrahman AH. Corynebacterium pseudotuberculosis: disease prevalence, lesion distribution, and diagnostic comparison through microbiological culture and molecular diagnosis. AJVS. 2016; 51(2): 189-198.

Bauer AW, Kirby WMM, Sherris JC, Turck M. Antibiotic susceptibilty testing by a standardized single disk method. Am J Clin Pathol. 1966; 45: 493.

Bastos BL, Portela RWD, Dorella FA, Ribeiro D, Seyffert N, Castro TLP, Miyoshi A, Oliveira SO, Meyer R, Azevedo V. Corynebacterium pseudotuberculosis: immunological responses in animal models and zoonotic potential. J Clin Cell Immunol. 2012; S4:005: doi:10.4172/2155-9899.S4-005.

CLSI. Performance Standarts for Antimicrobial Susceptibility Testing; 23rd informational supplement. CLSI M100- S23. Clinical and Laboratory Standards Institute, Wayne, PA.

Dorella FA, Pacheco LGC, Olivera SC, Miyashi A, Azevedo V. Corynebacterium pseudotuberculosis: microbiology, biochemical properties, pathogenesis and molecular studies of virulence. Vet Res. 2006; 37: 201-218.

Fernández EP, Vela AI, Las Heras A, Domínguez L, Fernández-Garayzábal JF, Moreno MA. Antimicrobial susceptibility of corynebacteria isolated from ewe's mastitis. Int J Antimicrob Agents. 2001; 18: 571- 574.

İlhan Z. Koyunlarda Corynebacterium pseudotuberculosis'in ELISA ve dot-blot ELISA ile teşhisi. Turk J Vet Anim Sci. 2003; 27(6): 1327-1333

Kuria JK, Holstad G. A seroepidemiological investigation of Corynebacterium pseudotuberculosis infection in sheep flocks in southern Norway. Acta Vet Scand. 1989; 30: 107-108.

Lee S, Siddiqui R, Khan NA. Animals living in polluted environments are potential source of antimicrobials against infectious agents. Pathogens Glob Health. 2012; 106 (4): 218-223.

Middleton MJ, Epstein WM, Gregory GG. Caseous lymphadenitis on Flinders Island: prevalence and management surveys. Aust Vet J. 1991; 68: 311-312.

Muckle CA, Gyles CL. Characterization of strains of Corynebacterium pseudotuberculosis. Can J Comp Med. 1982; 46: 206-208.

OIE. World health Organisation for Animal Health. Available at: http://www.oie.int/hs2/sit_mald_ cont.asp?c_mald $=156$ andc_cont $=6$ andannee $=2004$. 2009; (Accession date: 02.02.2020).

Parin U, Kırkan Ş, Ural K, Savaşan S, Erbaş G, Gültekin M, Yüksel HT, Balıkçı C. Molecular identification of
Corynebacterium pseudotuberculosis in sheep. Acta Vet Brno. 2018; 87: 3-8.

Pepin M, Boisrame A, Marly J. Corynebacterium psendotuberculosis: biochemical properties, production of toxin and virulence of ovine and caprine strains. Ann Rech Vet. 1989; 20 : 111-115.

Quinn PJ, Markey BK, Leonard FC, Fitzpatrick ES, Fanning S, Hartigan PJ. Veterinary Microbiology and Microbial Disease. 2nd ed. Wiley-Blackwell, West Sussex, UK. 2011; pp. 207-212.

Robaj A, Hamidi A, Bytyqi H, Sylejmani D. Frequency and antimicrobial susceptibility of bacterial isolates from caseous lymphadenitis in sheep in Kosovo. Bulgarian J Agri Sci. 2017; 23(6): 1033-1036.

Sa MCA, Veschi JLA, Santos GB, Amanso ES, Oliveira SAS, Mota RA, Veneroni-Gouveia G, Costa MM. Activity of disinfectants and biofilm production of Corynebacterium psendotuberculosis. Pesq Vet Bras. 2013; 33(11): 1319-1324.

Sakmanoğlu A, Hadimli HH, Erganiş E, Pınarkara Y, Sayın Z, Kav K. Koyunlardan izole edilen Corynebacterium pseudotuberculosis suşlarının identifikasyonu ve antibiyotiklere duyarlılıkları. Eurasian J Vet Sci. 2015; 31(2): 116-121.

Stanford K, Brogden KA, McClelland LA, Kozub GC, Audibert F. The incidence of caseous lymphadenitis in Alberta sheep and assessment of impact by vaccination with commercial and experimental vaccines. Can J Vet Res. 1998; 62: 38-43.

WHO. World Health Organization. https://www.who.int/newsroom/detail/17-01-2020-lack-of-new-antibioticsthreatens-global-efforts-to-contain-drug-resistantinfections.2020; (Accession date: 03.02.2020). 